\title{
Dons et legs
}

\section{Christophe Didier}

\section{(2) OpenEdition}

Journals

Édition électronique

URL : http://journals.openedition.org/rbnu/1283

DOI : $10.4000 /$ rbnu.1283

ISSN : 2679-6104

\section{Éditeur}

Bibliothèque nationale et universitaire de Strasbourg

\section{Édition imprimée}

Date de publication : 1 novembre 2015

Pagination : 6-7

ISBN : 9782859230616

ISSN : 2109-2761

\section{Référence électronique}

Christophe Didier, «Dons et legs », La Revue de la BNU [En ligne], 12 | 2015, mis en ligne le 01 mars 2020, consulté le 12 décembre 2020. URL : http://journals.openedition.org/rbnu/1283 ; DOI : https:// doi.org/10.4000/rbnu. 1283

\section{(C) $10(0$}

La Revue de la BNU est mise à disposition selon les termes de la Licence Creative Commons Attribution - Pas d'Utilisation Commerciale - Partage dans les Mêmes Conditions 4.0 International. 


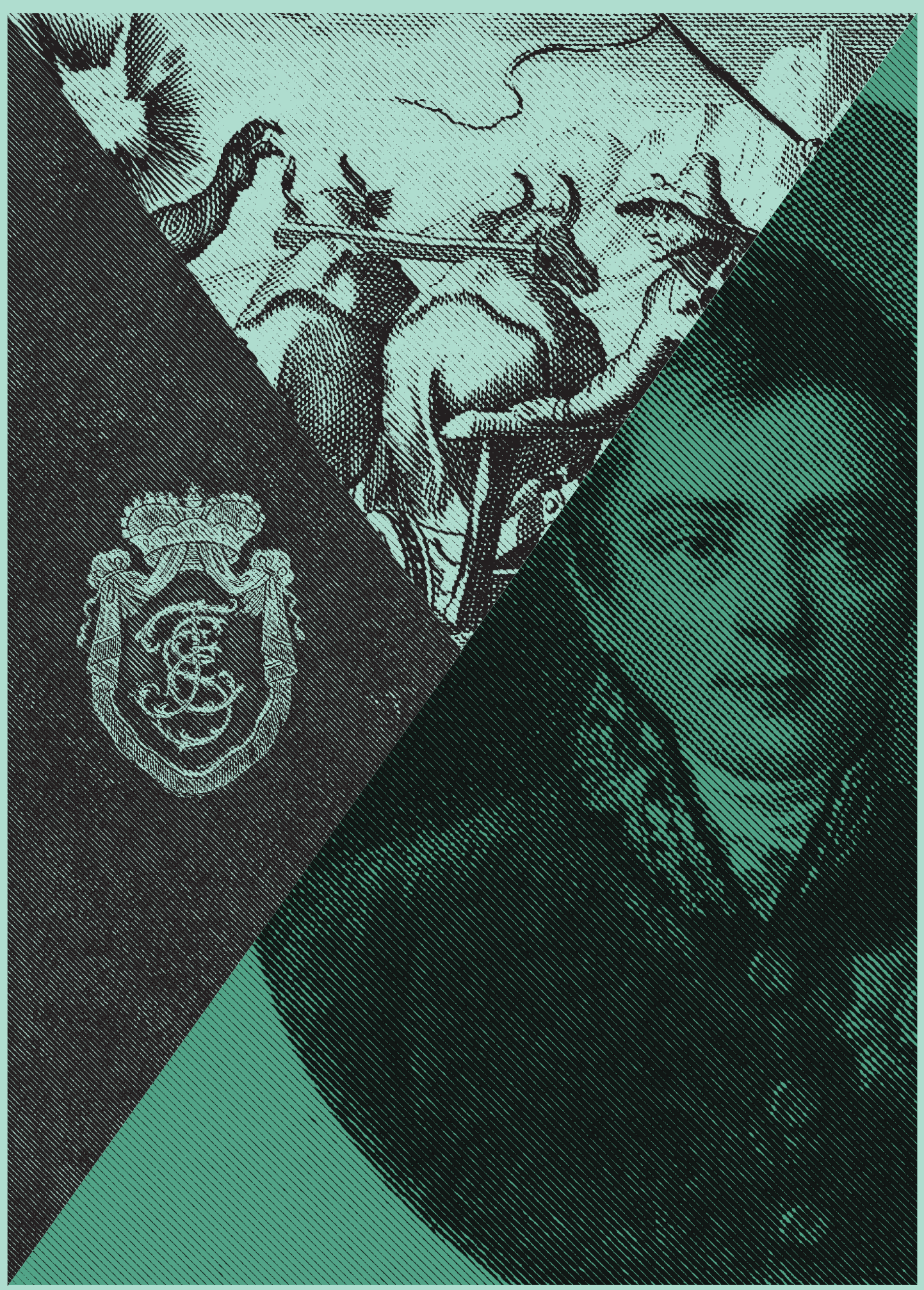




\section{Dons et legs}

Les dons, les legs, mais aussi les dépôts, ce que le jargon des professionnels appelle les " acquisitions non onéreuses ", sont une partie constitutive de l'essence même des bibliothèques et des musées. Il n'y a guère moyen de les ignorer quand on considère l'histoire de la BNU, née - en partie tout au moins - d'un appel général aux dons du monde entier pour reconstituer, après l'incendie du 24 août 1870 , une grande bibliothèque à Strasbourg. Plus généralement, ils contribuent à structurer, aux côtés de l'indispensable action de la puissance publique, l'offre culturelle et scientifique ; c'est ce que nous montre, de l'autre côté du Rhin en particulier, l'essor singulier des fondations ou des collections d'entreprises, qui relèvent certes d'une autre logique économique que de celle d'un don fait à une institution publique, mais n'en constituent pas moins à leur manière un don ou un legs à la collectivité, lorsqu'une collection d'art, par exemple, cesse d'être accessible à son seul propriétaire pour devenir un bien culturel destiné au plus grand nombre.

L'ambiguïté fondamentale d'un geste de pareille nature a souvent été soulignée, à juste titre : il est évident que le don ou le legs n'est jamais (ou rarement) totalement gratuit, et que des enjeux d'image, de pouvoir, d'intérêt ou de postérité se mêlent à la volonté pure et simple de donner. Il n'en demeure pas moins que dons, legs ou dépôts peuvent se révéler pleinement fondateurs, à la naissance de nouvelles institutions, stimulateurs de découvertes, de curiosités et de recherches. Et c'est précisément en ce sens que nous avons souhaité les envisager dans ce numéro de La Revue de la BNU. La thématique est d'ailleurs régulièrement l'objet de réflexions débattues au sein d'instances ou de publications spécialisées. Ainsi a eu lieu à Lyon, en 2007 et à l'initiative de l'ENSSIB et du Centre de conservation du livre d'Arles, une journée d'études sur les " dons et legs dans les bibliothèques publiques ", organisée dans le cadre de rencontres annuelles intitulées " Droit et patrimoine ". Plus près de nous, en 2014, l'association BiblioPat, là encore sous la forme d'une journée d'études intitulée " À prendre ou à laisser ? ", examinait les divers aspects, notamment techniques et opérationnels, à prendre en compte lorsqu'une institution publique s'apprête à recevoir un don. Si les côtés juridiques et techniques ne sont bien entendu pas absents des réflexions qu'on pourra lire dans ce dossier, c'est toutefois sous un angle plus général que nous avons souhaité examiner la question.

Le don peut en effet se résumer parfois en un accroissement d'unités ou de mètres linéaires - ce qui n'est pas minorer son intérêt, quand par exemple il dévoile, comme on le voit avec le fonds Wessenberg de la BNU, un pan de la mémoire de l'histoire européenne. Mais dans certains cas il est bien plus que cela : son objet se révèle alors pleinement fondateur, lorsque par exemple il est à l'origine d'un établissement nouveau, comme c'est le cas à Stuttgart, ou encore que son ampleur est telle qu'elle modifie la configuration initiale de l'établissement qui le reçoit. L'exemple de la Bibliothèque Warburg nous montre même un don fondateur d'une méthode de travail, d'un système de pensée dont l'établissement qui le renferme n'est que la traduction physique, ce qui à coup sûr représente la conséquence ultime qu'une démarche de ce genre puisse receler. L'exemple de la bibliothèque de Strasbourg, reconstituée ex nihilo sur la base initiale d'un appel aux dons, rappelle pour sa part combien ceuxci, d'un point de vue cette fois-ci plus politique, peuvent jouer un rôle de symbole dans la constitution d'une communauté et d'une société nouvelles - en l'occurrence l'Allemagne unifiée d'après 1870 et le fer de lance intellectuel qu'était son université. Que cette université et sa bibliothèque aient à leur tour servi de modèle à Aby Warburg pour élaborer sa propre collection et son classement original, à la base des recherches que sa propre collection a pu susciter, montre la dynamique intrinsèque née du don et du legs, lorsqu'ils sont envisagés comme promoteurs d'une pensée en marche - ce dont témoigne à son tour l'Institut Éric Weil, né de la constitution, puis du legs, de la bibliothèque d'un intellectuel influencé par la démarche de Warburg; ce dont témoigne aussi, à sa manière, l'héritage raisonné que Strasbourg, Tübingen et Stuttgart doivent au bibliothécaire et orientaliste Julius Euting, héritage toujours vivant et qui n'a pas fini de stimuler les recherches.

Le don ou le legs, souvent représentatifs de l'époque où ils ont été constitués, nous interrogent enfin sur la notion de patrimoine culturel. Qu'ils soient parfois vus comme de "précieux embarras ", comme on a pu le dire de la collection Vieusseux de Florence, ne doit pas faire oublier qu'ils nous obligent d'abord à réfléchir à la conservation de la mémoire de notre temps. Ils permettent aussi, en nous confrontant à la logique de la collection (et aux mentalités diverses des collectionneurs), de mesurer la dimension récurrente de ce phénomène culturel qui est à la base de tant de prestigieuses institutions actuelles. Les dons et legs, en d'autres termes, ne se suffisent pas à euxmêmes. La mémoire de leurs origines ne peut être bien servie que si les destinataires savent organiser au mieux leur réception, les faire vivre au meilleur sens du terme en les considérant comme des points de départ, bien plus que comme une fin en soi.

\section{Christophe Didier}

